\title{
Effects of inorganic arsenic on growth and microcystin production of a Microcystis strain isolated from an algal bloom in Dianchi Lake, China
}

\author{
GONG Yan ${ }^{1 \dagger}$, AO Hong $\mathrm{Yi}^{2 \dagger}$, LIU BiBo ${ }^{3}$, WEN Sheng ${ }^{4}$, WANG Zhi ${ }^{5}$, HU DingJing ${ }^{1}$, \\ ZHANG XingZhong ${ }^{1}$, SONG LiRong ${ }^{2} \&$ LIU JianTong ${ }^{2 *}$ \\ ${ }^{1}$ Institute of Agricultural Quality Standards \& Testing Technology, Hubei Academy of Agriculture Sciences, Wuhan 430064, China; \\ ${ }^{2}$ Institute of Hydrobiology, Chinese Academy of Sciences, Wuhan 430072, China; \\ ${ }^{3}$ Department of Resourses and Environment Engineering, Henan Institute of Engineering, Zhengzhou 451191, China; \\ ${ }^{4}$ National Institute of Nutrition and Food Safety, Chinese Center for Disease Control and Prevention, Beijing 100050, China; \\ ${ }^{5}$ Institute of Agricultural Resource and Environmental Sciences, Jiangsu Academy of Agricultural Sciences, Nanjing 210014, China
}

Received January 13, 2011; accepted May 9, 2011

\begin{abstract}
Our previous data have shown that inorganic arsenic concentrations were high in Dianchi Lake, China, where Microcystis blooms often occur. To explore the relationship between arsenic and the growth of Microcystis, the effects of arsenite [As(III)] and arsenate $[\mathrm{As}(\mathrm{V})]$ on the growth and toxin production of $M$. aeruginosa strain FACHB 905 were tested. Results showed that $M$. aeruginosa FACHB 905 was tolerant to inorganic arsenic and its growth was not inhibited when the concentration of As(III) was below $10^{-5} \mathrm{~mol} \mathrm{~L}^{-1}$ or that of $\mathrm{As}(\mathrm{V})$ below $10^{-3} \mathrm{~mol} \mathrm{~L}^{-1}$. Total microcystin production was stimulated in the presence of $10^{-7} \mathrm{~mol} \mathrm{~L}^{-1}$ As(III) and the response of this M. aeruginosa strain to As(III) seemed to be a typical inverted U-shaped hormesis. The content increase of microcystin-LR per cell indicated that the toxicity was enhanced as M. aeruginosa FACHB 905 was exposed to As(V). Considering the relatively high concentration of inorganic arsenic in Dianchi Lake ( $139 \mu \mathrm{g} \mathrm{L}^{-1}$ in epilimnetic water), the origin of the $M$. aeruginosa strain, inorganic arsenic favors survival of M. aeruginosa FACHB 905 and may stimulate its microcystin production and cellular toxicity.
\end{abstract}

inorganic arsenic, cyanobacteria, Microcystis aeruginosa, microcystin

Citation: Gong Y, Ao H Y, Liu B B, et al. Effects of inorganic arsenic on growth and microcystin production of a Microcystis strain isolated from an algal bloom in Dianchi Lake, China. Chinese Sci Bull, 2011, 56: 2337-2342, doi: 10.1007/s11434-011-4576-y

Arsenic is a ubiquitous toxic element in aquatic environments and its residence time in freshwater has been estimated at about 50 years [1]. The main arsenic species, including arsenate $[\mathrm{As}(\mathrm{V})]$, arsenite $[\mathrm{As}(\mathrm{III})]$, monomethylarsonic acid (MMAA), and dimethylarsinic acid (DMAA), have been found to be toxic to phytoplankton at different potencies and different species have different effects [2-5]. As(III) inhibits the incorporation of carbon into glutamate [2]. $\mathrm{As}(\mathrm{V})$ inactivates the phosphate transport system and

\footnotetext{
† These authors contributed equally to this work.

* Corresponding author (email: jtliu@ihb.ac.cn)
}

glucose metabolism, because of its similar structure to phosphate, and is readily co-transported into the cell $[5,6]$. Methylated species are shown to be less toxic or even non-toxic and, therefore, are regarded as detoxified products of some algae $[7,8]$. Previous studies indicated that algal sensitivity to inorganic arsenic may be species specific $[6,9,10]$.

Microcystis is a dominant cyanobacterium that blooms in the hypertrophic Dianchi Lake, Kunming, China [11]. A previous survey of this lake showed that the inorganic arsenic concentration (arsenate plus arsenite) was $139 \mu \mathrm{g} \mathrm{L}^{-1}$ in epilimnetic water and $332 \mathrm{mg} \mathrm{kg}^{-1}$ in sediment (data not shown). It is still unclear whether the occurrence of Micro- 
cystis blooms in the lake is linked with arsenic abundance, and whether arsenic affects the toxin production of Microcystis species, if the linkage exists. The effects of As(III) and $\mathrm{As}(\mathrm{V})$ on growth and toxin production of $M$. aerugino$s a$, isolated from a harmful algal bloom, were tested in the present study.

\section{Materials and methods}

\subsection{Growth experiments}

The axenic culture of unicellular $M$. aeruginosa FACHB 905 (FACHB-collection, Chinese Academy of Sciences, China) isolated from the epilimnetic water of Dianchi Lake [12] was maintained in BG-11 medium under continuous illumination at $(25 \pm 1)^{\circ} \mathrm{C}$ at a light intensity of $40-55 \mu \mathrm{mol}$ photon $\mathrm{m}^{-2} \mathrm{~s}^{-1}$ by cool white fluorescent light. All experimental batch cultures were prepared in 2.5-L glass flasks containing $2.0 \mathrm{~L}$ medium with Microcystis cultures at an initial concentration of $\sim 10^{6}$ cells $\mathrm{mL}^{-1}$. The cultures were aerated with $0.22 \mu \mathrm{m}$ filtered air. $\mathrm{As}$ (III) $\left(\mathrm{Na}_{3} \mathrm{AsO}_{3}\right.$, A.S., China) was added to the culture media at concentrations ranging from $10^{-8}$ to $10^{-4} \mathrm{~mol} \mathrm{~L}{ }^{-1}$, and $\mathrm{As}(\mathrm{V})\left(\mathrm{Na}_{2} \mathrm{HAsO}_{4} \cdot 7 \mathrm{H}_{2} \mathrm{O}\right.$, Alfa Aesar, USA) was utilized at concentrations ranging from $10^{-8}$ to $10^{-3} \mathrm{~mol} \mathrm{~L}^{-1}$. The higher concentrations of arsenic, such as $10^{-4} \mathrm{~mol} \mathrm{~L}^{-1} \mathrm{As}(\mathrm{III})$ and $10^{-3} \mathrm{~mol} \mathrm{~L}^{-1} \mathrm{As}(\mathrm{V})$, were applied in this study to explore the inhibitory threshold doses of arsenic for the growth of $M$. aeruginosa FACHB 905. Culture in the same growth medium without any arsenic species was used as the control. Each treatment was performed in triplicate. The stock bottles and culture flasks were soaked in $5 \%(\mathrm{v} / \mathrm{v}) \mathrm{HNO}_{3}$ for $48 \mathrm{~h}$ and sterilized with ozone for $20 \mathrm{~min}$ prior to use. Culture media were autoclaved for a minimum of $30 \mathrm{~min}$ at $121^{\circ} \mathrm{C}$.

\subsection{Determination of growth and biomass parameters}

Subsamples were taken every 2-3 d, and cell density was monitored at $A_{680}$ with a UV-visible spectrophotometer (Hitachi U-3400, Japan). Direct cell counts were enumerated using a hemacytometer. And a highly linear correlation between optical density and direct cell counts $\left(n=27, R^{2}=0.9926\right)$ was observed. Each subsample $(50 \mathrm{~mL})$ was filtered through a pre-weighed glass fiber filter (GF/C, Whatman, UK) under low vacuum pressure $(0.1 \mathrm{MPa})$. Cells collected on the filters were used for wet weight analysis, and then for chlorophyll analysis according to the methanol extract method [13]. The filtrate was used for analysis of $\mathrm{pH}$ and orthophosphate content. $\mathrm{pH}$ was determined with a $\mathrm{pH}$ electrode (Orion $230 \mathrm{~A}^{+}$; Thermo, USA) and soluble orthophosphate was measured in the presence of $\mathrm{As}(\mathrm{V})$ as described previously [14].

\subsection{Analysis of microcystins using HPLC}

Fifty milliliter of the sample was used for cell collection with the same procedure as described above. The filters were preserved at $-20^{\circ} \mathrm{C}$ prior to microcystin analysis. Microcystins were isolated from cells on the filters based on the method by Ramanan et al. [15]. Each test solution was analyzed directly by HPLC with photodiode array ultraviolet (HPLC-PDA-UV) detection. Separation was accomplished under reversed-phase isocratic conditions with an octadecyl silica (ODS) column (Cosmosil 5C18-AR, 4.6×150 mm; Nacalai, Japan) and a mobile phase of methanol: $0.01 \%$ TFA (55:45). The flow rate was $1 \mathrm{~mL} \mathrm{~min}^{-1}$. Microcystins were identified from their characteristic spectra. Quantification was carried out using peak areas of the test samples and comparing them with those of the standards available at $238 \mathrm{~nm}$. The microcystin standards (MC-LR, MC-RR and $\left.\left[\mathrm{Dha}^{7}\right] \mathrm{MC}-\mathrm{LR}\right)$ were obtained from Kanto Reagents (Japan). The HPLC-PDA system was an Agilent 1100 series.

\subsection{Statistics}

Statistical analysis was carried out with Microcal Origin (version 6.1) software. Student's $t$-test was performed to compare results obtained from controls and treatment cultures. In particular, paired $t$-tests were conducted on the control and treatment curves to determine the differences following exposure. Normality and homogeneity of variances was checked before statistical tests, and a significance level of $5 \%$ was adopted in all statistical tests.

\section{Results}

\subsection{Effects of arsenic species on growth patterns}

The growth curves of $M$. aeruginosa FACHB 905 exposed to $\mathrm{As}(\mathrm{III})$ at $10^{-8}-10^{-5} \mathrm{~mol} \mathrm{~L}^{-1}$, as shown in Figure 1, were similar to that of the control, but different from those treated

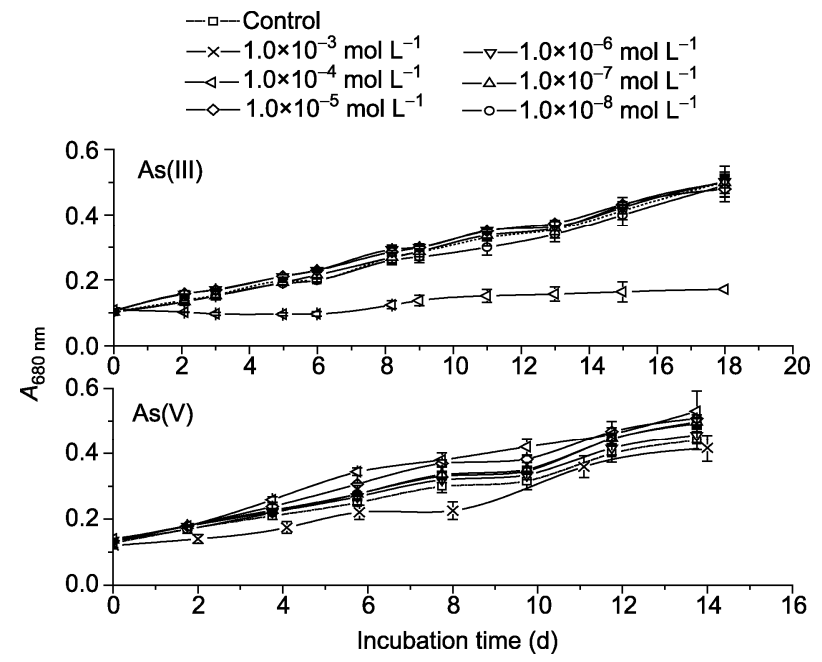

Figure 1 Growth curves of $M$. aeruginosa FACHB 905 in the presence of various concentrations of inorganic arsenic. Data presented as mean \pm standard deviation $(n=3)$. 
with $10^{-4} \mathrm{~mol} \mathrm{~L}^{-1} \mathrm{As}(\mathrm{III})$. In the presence of As(III) at $10^{-4}$ $\mathrm{mol} \mathrm{L}^{-1}$, there was no growth sign of $M$. aeruginosa FACHB 905 within the first $6 \mathrm{~d}$, and most cells died during this period (Figure 1). Then a slow recovery growth was found on the following days. $\mathrm{pH}$ in the medium decreased from $8.48 \pm$ 0.11 to $7.83 \pm 0.03$ in the first $2 \mathrm{~d}$ when cells were exposed to As(III) at $10^{-4} \mathrm{~mol} \mathrm{~L}^{-1}$, which indicated that most cells died in the first $2 \mathrm{~d}$. However, $\mathrm{pH}$ measured in other treatments increased gradually during the test (data not shown). Compared with the control, the treatments by $\mathrm{As}(\mathrm{V})$ did not show any obvious effect on growth $(P>0.05$, two-sample paired $t$-test), even in the presence of $\mathrm{As}(\mathrm{V})$ at $10^{-3} \mathrm{~mol} \mathrm{~L}^{-1}$ in the culture medium.

\subsection{Chlorophyll $a$ content}

The effects of arsenic on the chlorophyll $a$ content of $M$. aeruginosa FACHB 905 were different in respect to the arsenic species and concentrations (Figure 2). Except at $10^{-3}$ mol L ${ }^{-1}$, the presence of $\mathrm{As}(\mathrm{V})$ in the culture enhanced chlorophyll $a$ yields, with the highest level at $10^{-4} \mathrm{~mol} \mathrm{~L}^{-1}$ As(V). At $10^{-4} \mathrm{~mol} \mathrm{~L}^{-1} \mathrm{As}(\mathrm{III})$, a decrease in chlorophyll $a$ content, shown in Figure 2, indicated that As(III) had some inhibitory effect on the photosynthesis of M. aeruginosa.

\subsection{Orthophosphate analysis}

In the treatment of $10^{-4} \mathrm{~mol} \mathrm{~L}^{-1} \mathrm{As}(\mathrm{III})$, orthophosphate content increased along with the culture time within the first day, and reached up to the maximum value $(145 \%$ of the initial concentration) on day 6. Compared with the control, all of the treatments with $\mathrm{As}(\mathrm{V})$, except at $10^{-8} \mathrm{~mol} \mathrm{~L}^{-1}$, showed a peak value of orthophosphate on the 2 nd day, and orthophosphate levels in the media were shown to be higher at the end (Figure 3). These results indicated a decrease in orthophosphate uptake in the presence of $\mathrm{As}(\mathrm{V})$.

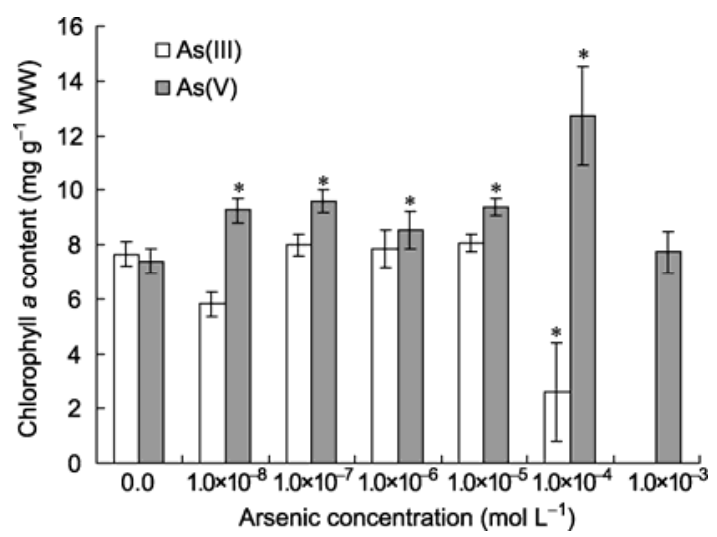

Figure 2 Clorophyll $a$ content of $M$. aeruginosa FACHB 905 on day 15, shown for cells grown with various concentrations of inorganic arsenic. Data presented as mean \pm standard deviation $(n=3)$. WW indicates wet weight of the cynobacterium. * indicates a significant difference from the control $(P<0.05)$.

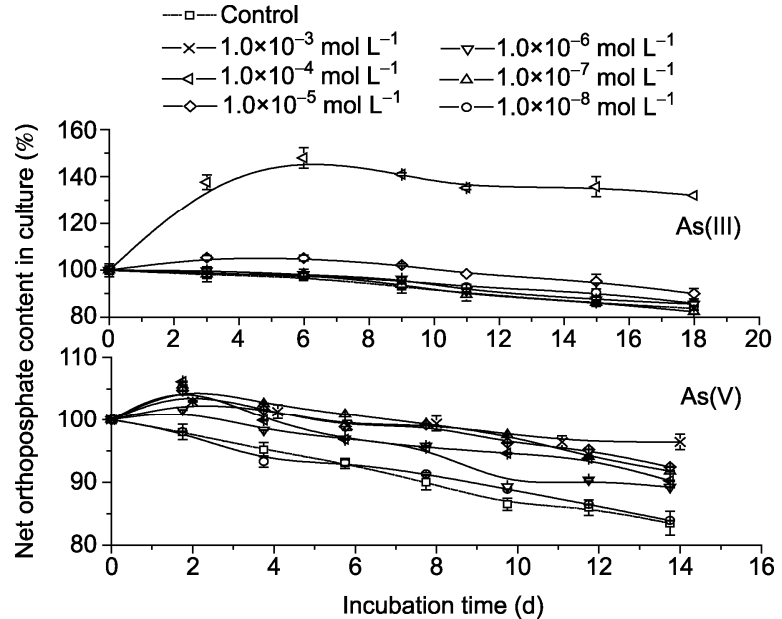

Figure 3 Net orthophosphate content in the medium, shown as a percentage of the value at the beginning of the experiment, for $M$. aeruginosa FACHB 905 grown with various concentrations of inorganic arsenic. Data presented as mean \pm standard deviation $(n=3)$.

\subsection{Microcystin production}

The strain $M$. aeruginosa FACHB 905 produces two main toxins: microcystin (MC)-LR and $\left[\mathrm{Dha}^{7}\right] \mathrm{MC}-\mathrm{LR}$. Analysis of cellular microcystins showed that a concentration of As(III) at $10^{-4} \mathrm{~mol} \mathrm{~L}^{-1}$ inhibited production of both MC-LR and $\left[\mathrm{Dha}^{7}\right] \mathrm{MC}-\mathrm{LR}$, and the toxin yield was lowest on day 6 (Figure 4(a) and (b)). Total microcystin yields after As(III) treatment followed an inverted U-shaped pattern, with a peak value of $(0.71 \pm 0.03) \mathrm{mg} \mathrm{g}^{-1}$ wet weight in the presence of $10^{-7} \mathrm{~mol} \mathrm{~L}^{-1} \mathrm{As}(\mathrm{III})$ (Figure 5). With respect to $\mathrm{As}(\mathrm{V})$ treatment, production of MC-LR was stimulated, while [Dha $\left.{ }^{7}\right] \mathrm{MC}-\mathrm{LR}$ content per cell was inhibited at all concentrations of As(V) (Figure 4(c) and (d), $P<0.01$, two-sample paired $t$-test). Total microcystin was stimulated by $\mathrm{As}(\mathrm{V})$ at $10^{-5}$ and $10^{-4} \mathrm{~mol} \mathrm{~L}^{-1}$ (Figure 5).

\section{Discussion}

Few reports on the toxicity of arsenic species to Microcystis species have been documented, although studies on uptake and transformation of arsenic species by other phytoplankton have been performed [3,16,17]. In the present study, the inhibitory threshold concentration of As(III) to growth of $M$. aeruginosa FACHB 905 in culture was between $10^{-5}$ and $10^{-4} \mathrm{~mol} \mathrm{~L}^{-1}$ (Figure 1). The insensitivity of M. aeruginosa FACHB 905 to As(III) was similar to that of the bacterial strains, such as Staphylococcus aureus and Escherichia coli [18], but highly different from that of some marine phytoplankton [7]. The recovery growth of $M$. aeruginosa FACHB 905 occurred after $6 \mathrm{~d}$ exposure to $10^{-4} \mathrm{~mol} \mathrm{~L}^{-1} \mathrm{As}(\mathrm{III})$. As(III) was quickly oxidized to $\mathrm{As}(\mathrm{V})$ by oxygen in the medium, which was a spontaneous and exergonic reaction with an estimated standard Gibbs free energy change of 


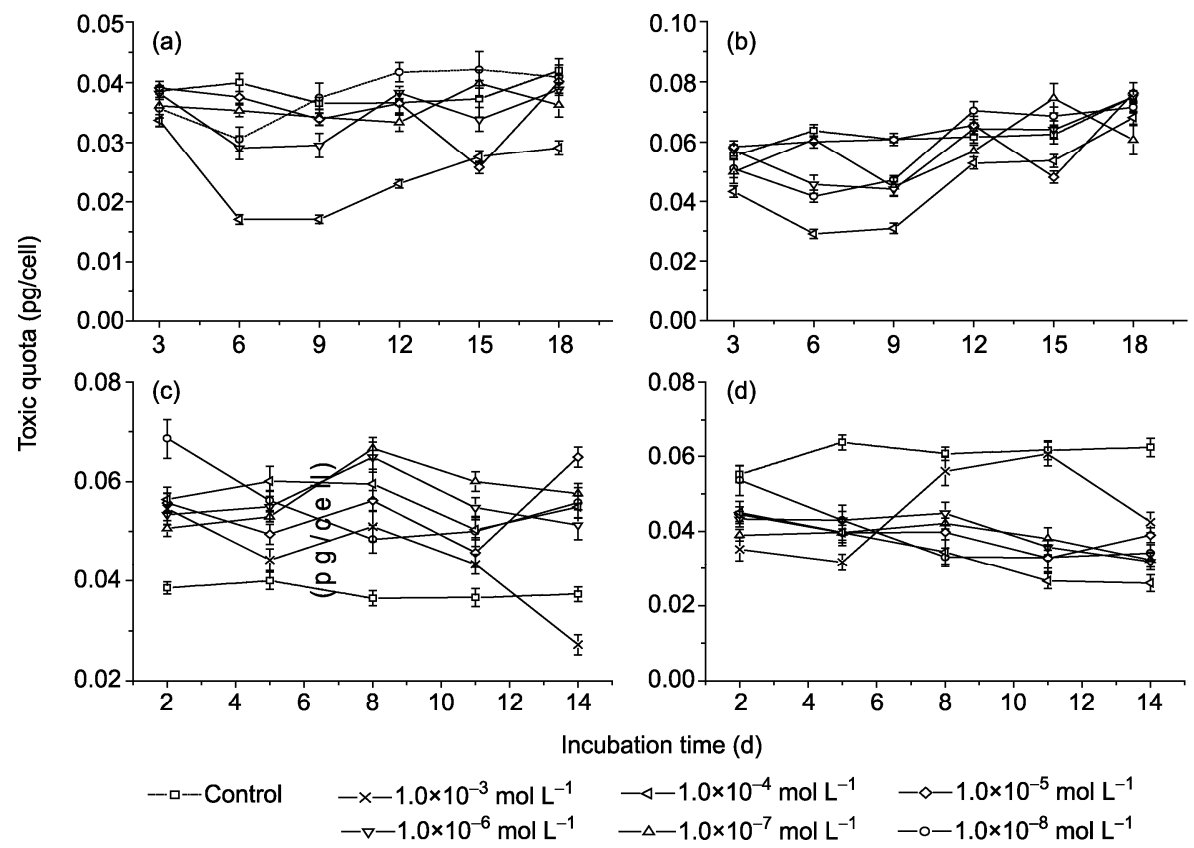

Figure 4 Effects of inorganic arsenic on microcystin (MC) content per cell in M. aeruginosa FACHB 905. (a) MC-LR content in the presence of As(III); (b) $\left[\mathrm{Dha}^{7}\right] \mathrm{MC}-\mathrm{LR}$ content in the presence of As(III); (c) MC-LR content in the presence of As(V); (d) [Dha $]$ MC-LR content in the presence of As(V). Data presented as mean \pm standard deviation $(n=3)$.

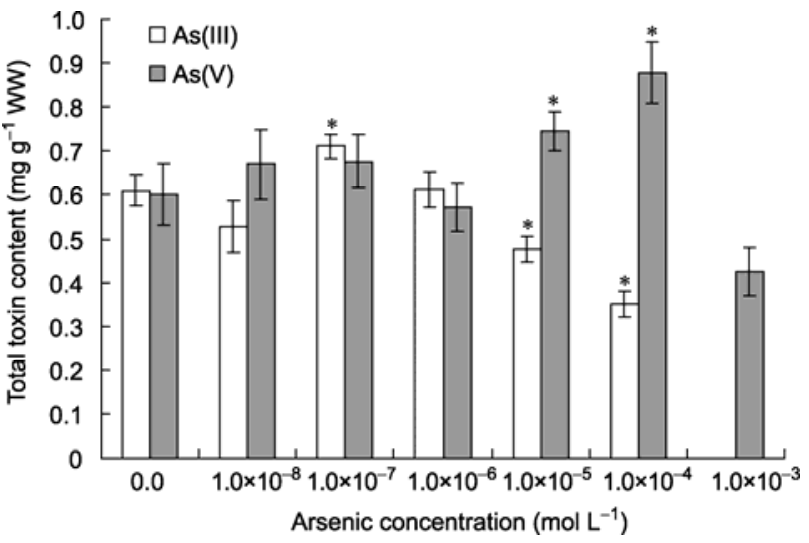

Figure 5 Total microcystin levels on day 15 in M. aeruginosa FACHB 905 grown with various concentrations of inorganic arsenic. WW indicates wet weight of the cyanobacterium. Data presented as mean \pm standard deviation $(n=3)$. * Indicates a significant difference from the control $(P<0.05)$.

$-40.82 \mathrm{kcal} / \mathrm{mol}$ [19]. There might be a physiological adaptation of an arsenic-tolerant organism [20,21]. It was reported that the stress proteins in some cyanobacterium and green alga were induced and helped repair denatured proteins and protect cells from damage under stressful conditions [22,23]. M. aeruginosa FACHB 905 might create a similar mechanism under arsenite stress, and develop the ability to recover and survive after the oxidization of As(III) to $\mathrm{As}(\mathrm{V})$. Such a mechanism needs to be examined further in future studies.

M. aeruginosa FACHB 905 was also shown to be tolerant to $\mathrm{As}(\mathrm{V})$ up to $10^{-3} \mathrm{~mol} \mathrm{~L}^{-1}$. Such tolerance of this
Microcystis strain to $\mathrm{As}(\mathrm{V})$ was much greater than that of many freshwater microalgae, such as Chlamydocapsa $c f$. peterfii $\left(\mathrm{EC}_{50}=10^{-6} \mathrm{~mol} \mathrm{~L}^{-1}\right)$ [24], Stichococcus bacillaris, which exhibited growth inhibition under $10^{-5} \mathrm{~mol} \mathrm{~L}^{-1} \mathrm{As}(\mathrm{V})$ [4], and Monoraphidium arcuatum (Kors.; 72-h $\mathrm{IC}_{50}$ of $8.06 \times$ $10^{-6} \mathrm{~mol} \mathrm{~L}^{-1}$ ) [3]. The higher tolerance of $M$. aeruginosa FACHB 905 to As(V) may be explained by one or both of the following mechanisms: alteration in phosphate transport or modification of the external toxicant. "Alteration in phosphate transport" could mean that the cyanobacterial cells exposed to arsenate might alter the phosphate transport system to uptake arsenate as little as possible, as demonstrated by the bacterium Escherichia coli [25]. As shown in Figure 3, decreased orthophosphate uptake could give some indirect evidence to support this presumption. The second mechanism could be that Microcystis might have the ability to modify the toxicity of the external arsenate. Some cyanobacteria could incorporate arsenate into their cells and reduce it, such as Synechococcus sp. [26] and Phormidium sp. [27,28]. Furthermore, an arsenate reductase was found in the cyanobacterium Synechocystis sp. PCC6803 [29,30].

In contrast to other As(III)- and As(V)-insensitive microorganisms, hepatoxic Microcystis species, causing liver damage or even liver hemorrhage, is a common group of bloom-forming cyanobacteria in eutrophic freshwaters worldwide [31]. At least 76 different microcystin analogues have been identified in natural blooms and laboratory cultures of cyanobacteria [32]. More specifically, MC-RR, LR and $\left[\mathrm{Dha}^{7}\right] \mathrm{MC}-\mathrm{LR}$ were commonly found in freshwater cyanobacterial blooms in China [33]. As described above, 
M. aeruginosa FACHB 905 mainly produces MC-LR and $\left[\mathrm{Dha}^{7}\right] \mathrm{MC}-\mathrm{LR}$. MC-LR is the most common and toxic variant of all the microcystins with an $\mathrm{LD}_{50}$ of $50 \mu \mathrm{g} \mathrm{kg}^{-1}$ [34], whereas the toxicity of [ $\left.\mathrm{Dha}^{7}\right] \mathrm{MC}-\mathrm{LR}$ is about one fifth of that of MC-LR [31]. Thus, it is important to analyze variation in all microcystin types resulting from exposure to inorganic arsenic in this study. The results from the present study revealed that $\mathrm{As}(\mathrm{V})$ had a significant stimulating effect on the cellular level of MC-LR (Figure 4(c)), enhancing the toxicity of this cyanobacterium. The factors that control the growth and toxin content of individual strains are still unknown, but may be related to the genetic regulation of cyanotoxin production [31]. On the other hand, $\mathrm{As}(\mathrm{V})$ at a concentration of $10^{-8}-10^{-4} \mathrm{~mol} \mathrm{~L}^{-1}$ mildly stimulated synthesis of chlorophyll $a$ in M. aeruginosa FACHB 905 (Figure 2). It has been found that microcystin was associated with the thylakoid membranes of $M$. aeruginosa, which suggested a close physiological association between microcystins and the photosynthetic machinery of the cell [35]. Microcystin stimulation had also been found in Microcystis TY-1 isolated from a lake in Taiwan [36], when the strain was exposed to arsenate (personal communication with Hong-Nong Chou, unpublished). Our findings suggested that both As (III) and As (V) took part in the physiological activity of $M$. aeruginosa FACHB 905, but it was presumed that these two inorganic arsenic species exhibited different uptake modes. As $(\mathrm{V})$ was taken up by the phosphate transport system, with some effects on the genetic regulation for microcystin production, while As(III) might be taken up by aquaglyceroporins [37] and inhibit net photosynthesis [2].

The response of total microcystin yield in this $M$. aeruginosa strain to $10^{-8}-10^{-4}$ mol L ${ }^{-1} \mathrm{As}(\mathrm{III})$ seemed to follow an inverted U-shaped hormetic pattern, as described by Stebbing [38], which varied from being enhanced at lower doses to being decreased (because of toxicity) at higher doses. The peak values detected in this study were $123 \%$ of the control when treated with $10^{-7} \mathrm{~mol} \mathrm{~L}^{-1} \mathrm{As}(\mathrm{III})$, which fell within the range of typical hormetic responses proposed by Calabrese and Baldwin [39] (Figure 5). It is well known that inorganic arsenic is generally the dominant species in natural waters [40]. The inorganic arsenic concentration of $139 \mu \mathrm{g} \mathrm{L}^{-1}$ in epilimnetic water of Dianchi Lake was $\sim 10^{-6}$ mol $\mathrm{L}^{-1}$, implying that inorganic arsenic species may favor survival of M. aeruginosa FACHB 905 in Dianchi Lake, as well as stimulating its microcystin production and cellular toxicity.

To our knowledge, the present study is the first report on the effects of inorganic arsenic on the growth and microcystin production of $M$. aeruginosa isolated from a harmful algal bloom in China. Results showed that M. aeruginosa FACHB 905 is an As(III)- and As(V)-tolerant cyanobacterium. The response of total toxin production to As(III) seemed to follow a typical inverted U-shaped hormesis and $\mathrm{As}(\mathrm{V})$ could stimulate MC-LR production. Further work is warranted to clarify whether arsenate affects cyanobacterial blooms and microcystin production in natural waters.

We gratefully acknowledge the editing and insightful comments on the manuscript of Profs. Dazhao Yu, Renhui Li and Zhan Yin. We also acknowledge the experimental advice and HPLC analysis of Dr. Xiaoguo Chen, and anonymous reviewers for their constructive comments on the draft manuscript. This work was supported by the State Key Laboratory of Freshwater Ecology and Biotechnology (2009FBZ09), National Major Science and Technology Program of China (2009ZX07104-005-03) and the Hubei Key Laboratory of Crop Diseases, Insect Pests and Weeds Control (2011CDIWC-1-1)

1 Klein D H. Fluxes, residence times, and sources of some elements to Lake Michigan. Water Air Soil Poll, 1975, 4: 3-8

2 Budd K, Casey J R, MacArthur J D. Arsenite toxicity and arsenite tolerance in the cyanobacterium Synechococcus leopoliensis. Can J Bot, 1986, 64: 2433-2440

3 Levy J L, Stauber J L, Adams M S, et al. Toxicity, biotransformation, and mode of action of arsenic in two freshwater microalgae (Chlorella sp. and Monoraphidium arcuatum). Environ Toxicol Chem, 2005, 24: 2630-2639

4 Pawlik-Skowronska B, Pirszel J, Kalinowska R, et al. Arsenic availability, toxicity and direct role of GSH and phytochelatins in As detoxification in the green alga Stichococcus bacillaris. Aquat Toxicol, 2004, 70: 201-212

5 Wängberg S A, Blanck H. Arsenate sensitivity in marine periphyton communities established under various nutrient regimes. J Exp Mar Biol Ecol, 1990, 139: 119-134

6 Planas D, Healey F P. Effects of arsenate on growth and phosphorus metabolism of phytoplanton. J Phycol, 1978, 14: 337-341

7 Sanders J G. Effects of arsenic speciation and phosphate concentration on arsenic inhibition of Skeletonema costatum (Bacillariophyceae). J Phycol, 1979, 15: 424-428

8 Hellweger F L, Farley K J, Lall U, et al. Greedy algae reduce arsenate. Limnol Oceanogr, 2003, 48: 2275-2288

9 Knauer K, Behra R, Hemond H. Toxicity of inorganic and methylated arsenic to algal communities from lakes along an arsenic contamination gradient. Aquat Toxicol, 1999, 46: 221-230

10 Bottino N R, Newman R D, Cox E R, et al. The effects of arsenate and arsenite on the growth and morphology of the marine unicellular algae Tetraselmis chui (Chlorophyta) and Hymenomonas carterae (Chrysophyta). J Exp Mar Biol Ecol, 1978, 33: 153-168

11 Li H, Hou G, Dakui F, et al. Prediction and elucidation of the population dynamics of Microcystis spp. in Lake Dianchi (China) by means of artificial neural networks. Ecol Inform, 2007, 2: 184-192

12 Wu Z X, Gan N Q, Song L R. Genetic diversity: Geographical distribution and toxin profiles of Microcystis strains (Cyanobacteria) in China. J Integr Plant Biol, 2007, 49: 262-269

13 MacKinney G. Absorption of light by chlorophyll solutions. J Biol Chem, 1941, 140: 315-322

14 Johnson D L. Simultaneous determination of arsenate and phosphate in natural waters. Environ Sci Technol, 1971, 5: 411-414

15 Ramanan S, Tang J, Velayudhan A. Isolation and preparative purification of microcystin variants. J Chromatogr A, 2000, 833: 103-112

16 Cullen W R, Harrison L G, Li H, et al. Bioaccumulation and excretion of arsenic compounds by a marine unicellular alga, Polyphysa peniculus. Appl Organomet Chem, 1994, 8: 313-324

17 McSheehy S, Szpunar J. Speciation of arsenic in edible algae by bi-dimensional size-exclusion anion exchange HPLC with dual ICPMS and electrospray MS/MS detection. J Anal At Spectrom, 2000, 15: 79-87

18 Silver S, Budd K, Leahy K M, et al. Inducible plasmid-determined resistance to arsenate, arsenite and antimony(III) in Escherichia coli and Staphylococcus aureus. J Bacteriol, 1981, 146: 983-996

19 Razoa L M D, Quintanilla-Vegaa B, Brambila-Colombresb E, et al. Stress 
Proteins Induced by Arsenic. Toxicol Appl Pharm, 2001, 177: 132-148

20 Creed I F, Havas M, Trick C G. Effects of arsenate on growth of nitrogen- and phosphorus-limited Chlorella vulgaris (Chlorophyceae) isolates. J Phycol, 1990, 26: 641-650

21 Walker-Caprioglio H M, Rodriguez R J, Parks L W. Recovery of Saccharomyces cerevisiae from ethanol-induced growth inhibition. Appl Environ Microbiol, 1985, 50: 685-689

22 Huckauf J, Nomura C, Forchhammer K, et al. Stress responses of Synechocystis sp. strain PCC 6803 mutants impaired in genes encoding putative alternative sigma factors. Microbiology, 2000, 146: 2877-2889

23 Lewis S, Donkin M E, Depledge M H. Hsp70 expression in Enteromorpha intestinalis (Chlorophyta) exposed to environmental stressors. Aquat Toxicol, 2001, 51: 277-291

24 Wängberg S-A, Blanck H. Arsenate sensitivity in marine periphyton communities established under various nutrient regimes. J. Exp. Mar. Biol. Ecol, 1990, 139: 119-134

25 Bennett R L, Malamy M H. Arsenate resistant mutants of Escherichia coli and phosphate transport. Biochem Biophys Res Commun, 1970, 40: 496-503

26 Takahashi A, Kawakami H, Iwakiri K, et al. Some characteristics of arsenate transport in a marine cyanobacterium, Synechococcus sp. Appl Organomet Chem, 2001, 15: 291-298

27 Matsuto S, Kasuga H, Okumoto H, et al. Accumulation of arsenic in blue-green alga, Phormidium sp. Comp Biochem Physiol C, 1984, 78: 377-382

28 Takahashi A, Kawakami H, Bada A, et al. Effects of phosphate on arsenate inhibition in a marine cyanobacterium, Phormidium sp. Appl Organomet Chem, 2004, 4: 269-279

29 Li R, Haile J D, Kennelly P J. An arsenate reductase from Synecho- cystis sp. strain PCC 6803 exhibits a novel combination of catalytic characteristics. J Bacteriol, 2003, 185: 6780-6789

30 López-Maury L, Florencio F J, Reyes J C. Arsenic sensing and resistance system in the cyanobacterium Synechocystis sp. strain PCC 6803. J Bacteriol, 2003, 185: 5363-5371

31 Sivonen K, Jones G. Cyanobacterial toxins. In: Chorus I, Bartram J, eds. Toxic Cyanobacteria in Water: A Guide to Their Public Health Consequences, Monitoring and Management. London: World Health Organization, Routledge E \& FN Spon, 1999. 73-82

32 Acero J L, Rodriguez E, Meriluoto J. Kinetics of reactions between chlorine and the cyanobacterial toxins microcystins. Water Res, 2005, 39: 1628-1638

33 Chen W, Song L, Gan N, et al. Sorption, degradation and mobility of microcystins in Chinese agriculture soils: Risk assessment for groundwater protection. Environ Pollut, 2006, 144: 752-758

34 Dawson R M. The toxicology of microcystins. Toxicon, 1998, 36: 953-962

35 Shi L, Carmichael W W, Miller I. Immuno-gold localization of hepatotoxins in cyanobacterial cells. Arch Microbiol, 1995, 163: 7-15

36 Lee T H, Chen Y M, Chou H N. First report of microcystins in Taiwan. Toxicon, 1998, 36: 247-255

37 Rosen B P. Biochemistry of arsenic detoxification. FEBS Lett, 2002, 529: 86-92

38 Stebbing A R D. Hormesis: The stimulation of growth by low levels of inhibitors. SciTotal Environ, 1982, 22: 213-234

39 Calabrese E J, Baldwin L A. A quantitatively based methodology for the evaluation of hormesis. Hum Ecol Risk Assess, 1997, 3: 545-554

40 Smedley P L, Kinniburgh D G. A review of the source, behavior and distribution of arsenic in natural waters. Appl Geochem, 2002, 17: 517-568

Open Access This article is distributed under the terms of the Creative Commons Attribution License which permits any use, distribution, and reproduction in any medium, provided the original author(s) and source are credited. 